\title{
Spectrum for UAS Control and Non-Payload Communications
}

Presented by:

Bob Kerczewski

Deputy Project Manager, Glenn Research Center, UAS in the NAS Project Spectrum Lead, Communication Sub-Project, UAS in the NAS Project

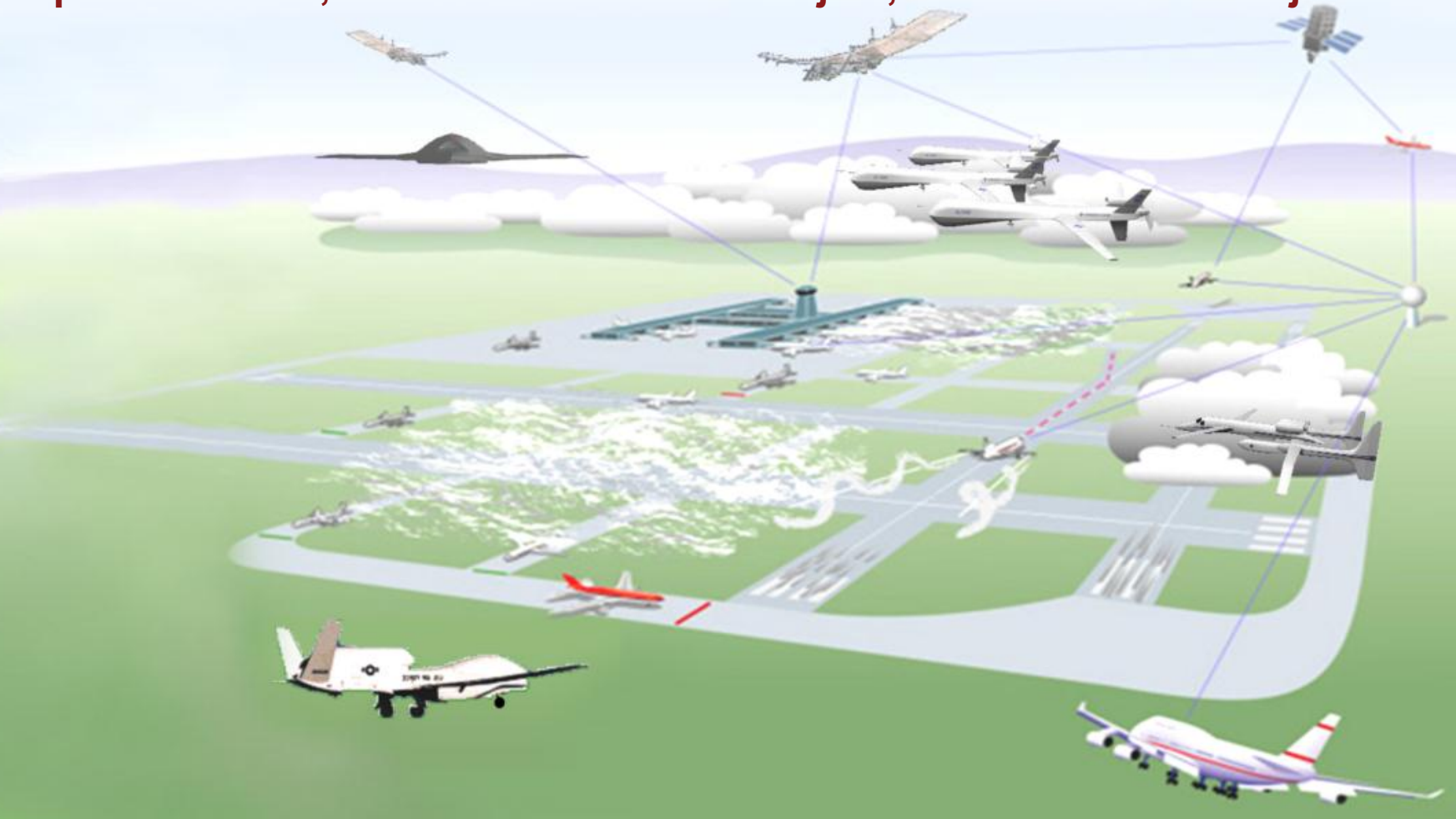




\section{Spectrum for UAS Control and Non-Payload Communications}

\section{OUTLINE}

- Introduction

- CNPC Spectrum Requirements

- Aviation Safety Spectrum in Recent Years

- CNPC Spectrum Status

- LOS

- BLOS

- LOS and BLOS Spectrum for UAS - Current Activities

- WRC-15 Agenda Item 1.5

- Band Planning

- Current Analyses for UAS BLOS CNPC

- Summary 


\section{Spectrum for UAS Control and Non-Payload Communications}

\section{INTRODUCTION}

\section{Unmanned Aircraft Systems (UAS) - What's Needed to Enable Integration into the National Airspace System (NAS)?}

- There is an increasing need to fly UAS in the NAS to perform missions of vital importance to National Security and Defense, Emergency Management, and Science as well as commercial applications (e.g. cargo transport)

- Eliminate or reduce critical technical barriers of integrating UAS into the NAS

- Separation Assurance/Sense and Avoid - the uncertainty surrounding the ability to interoperate in ATC environments and maintain safe separation from other aircraft in the absence of an on-board pilot.

- Human Systems Integration - lack of standards and guidelines with respect to UAS display/information as well as lack of Ground Control Station (GCS) design requirements to operate in the NAS.

- Certification - lack of airworthiness requirements and safety-related data specific to the full range of UAS, or for their avionics systems or other components

- Communications - lack of standard, certifiable data links and aviation safety spectrum to operate such links for civil UAS control communications. 


\section{Spectrum for UAS Control and Non-Payload Communications}

\section{What is CNPC - Control and Non-Payload Communications?}

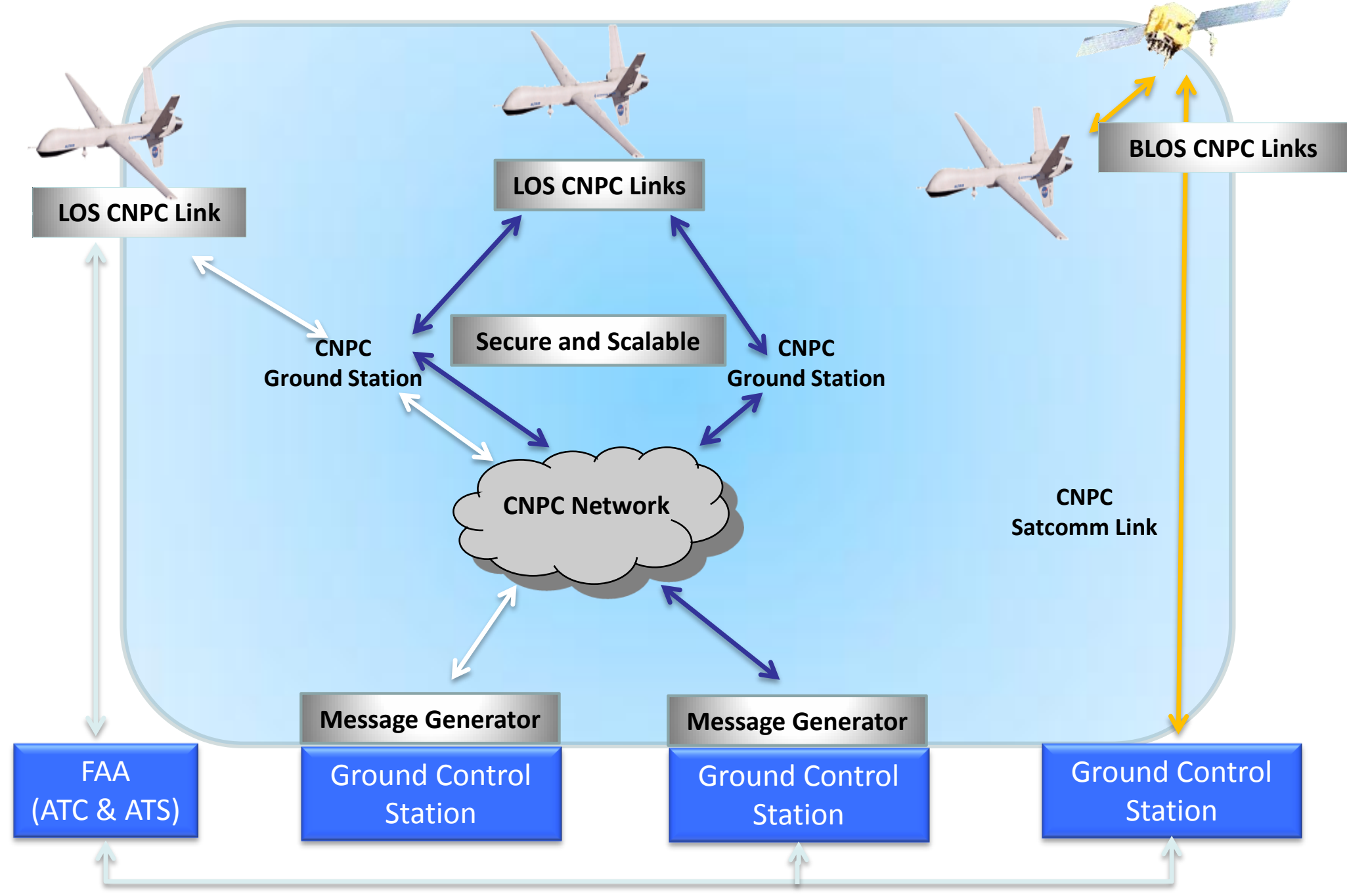

Possible Future ATC and ATS Ground Connectivity 


\section{Spectrum for UAS Control and Non-Payload Communications}

\section{CNPC Spectrum Requirements}

\section{Protected Aviation Spectrum is Required}

- The CNPC link supports safety critical functions. Loss or compromise of the CNPC link has potentially catastrophic consequences. Therefore, the International Civil Aviation Organization (ICAO) has determined that the CNPC links must operate over protected aviation spectrum, under International Telecommunications Union (ITU) designations:

- Aeronautical Mobile (Route) Service $(A M(R) S)$ for terrestrial CNPC

- Aeronautical Mobile Satellite (Route) Service (AMS(R)S) for satellite CNPC

- These are the 2 designations required to support "safety and regularity of flight" How Much Spectrum is Required?

- The Spectrum Requirements for UAS CNPC are officially defined by the ITU Radiocommunication Sector (ITU-R) for the purpose of defining spectrum allocations (ITU-R Report M.2171).

- Considering the data rate requirements and expected UA density estimated for the year 2030

- $34 \mathrm{MHz}$ for the terrestrial-based LOS CNPC

- $56 \mathrm{MHz}$ for the satellite based BLOS CNPC links. 


\section{Spectrum for UAS Control and Non-Payload Communications}

\section{Aviation Safety Spectrum in Recent Years}

\section{Looking back at WRC-2007}

New $A M(R) S$ allocations were made in three existing aviation bands:

- $112-117.975 \mathrm{MHz}$

Recognizing the increasing congestion in VHF in densely used airspace.

- 960-1164 MHz (L-Band)

Enable future digital ATC communications in this band - difficult since it is heavily used by navigation (DME, Mode S, UAT, TACAN). The "LDACS"

system is currently being developed and tested for such a possible future

- 5091-5150 MHz (C-Band)

This allocation supports airport surface communications known as

"AeroMACS". AeroMACS is nearing completion of standardization and is starting to be rolled out in the US.

- Agenda Item 1.3 for WRC-2012: consider spectrum requirements and possible regulatory actions, including allocations, in order to support the safe operation of unmanned aircraft systems (UAS).

The requirements for aviation safety communications are increasing, but available spectrum is hard to find. In recent WRCs, existing aviation bands are repurposed, requiring sharing between $A M(R) S$ services and existing services. 


\section{Spectrum for UAS Control and Non-Payload Communications}

\section{WRC-2012 CNPC Spectrum Outcome}

- WRC 2012 approved a new allocation for $A M(R) S$ for UAS LOS CNPC:

5030-5091 MHz (C-Band).

- WRC 2012 confirmed the $A M(R) S$ allocation for the 960-1164 MHz (L-Band).

\begin{tabular}{|c|c|}
\hline \multicolumn{2}{|r|}{ Allocation to services } \\
\hline Region 1 & Region 2 \\
\hline $5000-5010$ & $\begin{array}{l}\text { AERONAUTICAL MOBILE-SATELLITE (R) ADD 5.B103 } \\
\text { AERONAUTICAL RADIONAVIGATION }\end{array}$ \\
\hline \multicolumn{2}{|c|}{ RADIONAVIGATION-SATELLITE (Earth-to-space) } \\
\hline $5010-5030$ & $\begin{array}{l}\text { AERONAUTICAL MOBILE-SATELLITE (R) ADD 5.B103 } \\
\text { AERONAUTICAL RADIONAVIGATION }\end{array}$ \\
\hline \multicolumn{2}{|c|}{$\begin{array}{c}\text { RADIONAVIGATION-SATELLITE (space-to-Earth) (space-to-space) } \\
\text { 5.328B MOD 5.443B }\end{array}$} \\
\hline \multicolumn{2}{|c|}{ AERONAUTICAL MOBILE-SATELLITE (R) ADD 5.D103 } \\
\hline \multicolumn{2}{|c|}{ AERONAUTICAL RADIONAVIGATION } \\
\hline \multicolumn{2}{|r|}{ MOD 5.444} \\
\hline $\begin{array}{l}\mathbf{5 0 9 1 - 5 1 5 0} \\
\text { AERONAUTICAL I } \\
\text { AERONAUTICAL I } \\
\text { MOD 5.444 5.444A }\end{array}$ & $\begin{array}{l}\text { AERONAUTICAL MOBILE 5.444B } \\
\text { ГELLITE (R) ADD 5.B103 } \\
\text { GATION }\end{array}$ \\
\hline
\end{tabular}

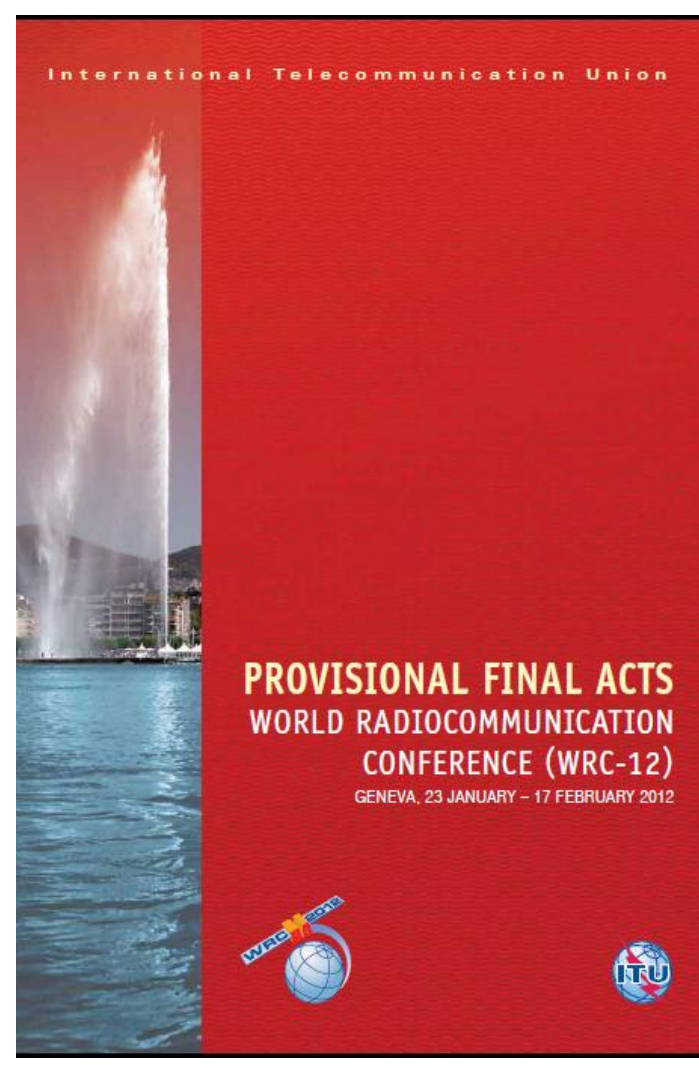

5.C103 The use of the frequency band $5030-5091 \mathrm{MHz}$ by the aeronautical mobile $(\mathrm{R})$ service is limited to internationally standardized aeronautical systems. Unwanted emissions from the aeronautical mobile (R) service in the frequency band 5 030-5 $091 \mathrm{MHz}$ shall be limited to protect RNSS system downlinks in the adjacent $5010-5030 \mathrm{MHz}$ band. Until such time that an appropriate value is established in a relevant ITU-R Recommendation, the e.i.r.p. density limit of $-75 \mathrm{dBW} / \mathrm{MHz}$ in the frequency band $5010-5030 \mathrm{MHz}$ for any $\mathrm{AM}(\mathrm{R}) \mathrm{S}$ station unwanted emission should be used. (wrc-12) 


\section{Spectrum for UAS Control and Non-Payload Communications}

\section{WRC-2012 CNPC Spectrum Outcome}

WRC 2012 approved a new agenda item (AI 1.5) for WRC 2015 for spectrum in the Fixed Satellite Service (FSS) bands for UAS CNPC (under Res. COM6/13)

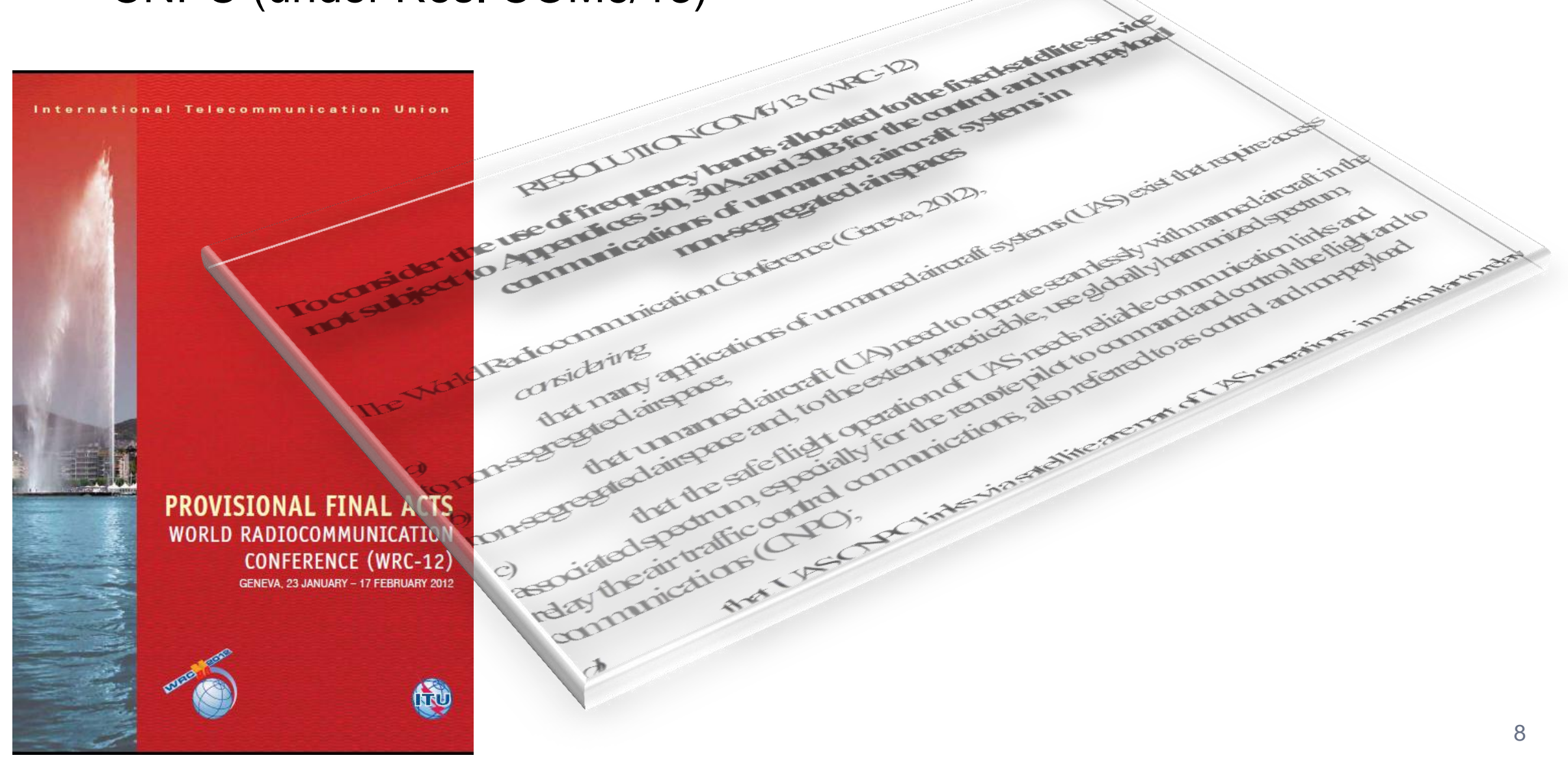




\section{Spectrum for UAS Control and Non-Payload Communications}

\section{Status of CNPC Spectrum}

\section{Line-of-Sight (LOS) Spectrum for CNPC}

- At the World Radiocommunications Conference in 2012 (WRC-12), allocations were made to $A M(R) S$ for UAS CNPC Communications.

- These allocations meet the $34 \mathrm{MHz}$ requirement

- Additional work is needed to define the parameters of the usage of these allocations for UAS CNPC

- Standards, band planning, system technical characteristics, etc.

\section{Beyond-Line-of-Sight (BLOS) Spectrum for CNPC}

- An AMS(R)S allocation exists that can provide satellite communications spectrum for UAS CNPC - but there are problems:

- It does not meet the $56 \mathrm{MHz}$ requirement

- No satellites exist in this allocation, none are currently planned, and a business case for such a system seems very difficult

- A feasible alternative is the use of existing satellite operating in the FSS Bands - in Ku-Band and Ka-band.

- The regulatory framework must be developed to enable use of FSS satellite communications for civil CNPC. 


\section{Spectrum for UAS Control and Non-Payload Communications}

\section{LOS and BLOS Spectrum for UAS - Current Activities}

WRC-15 Agenda Item 1.5 addresses the use of FSS bands for UAS CNPC satellite communications links: (WRC-12 Res. COM6/13)

"to consider, based on the results of the ITU-R studies, the possible regulatory actions to support the use of FSS frequency bands for the UAS CNPC links..., ensuring the safe operation of UAS CNPC links..."

- The inputs to WRC-15 addressing Al 1.5 will be developed through ITU-R Working Party 5B (WP 5B).

- RTCA SC-203 has been helping to coordinate inputs to the US WP5B, with participation from NASA, FAA, DoD, and industry.

An ITU-R document in WP5B is now being developed: "Working Document Towards a Draft New Report ITU-R M.[UAS-FSS] ."

- Sharing studies are being performed to address FSS bands under consideration:

- 10.7-12.75 GHz - interference from terrestrial services into UA earth station

- 14.0-14.5 GHz - interference from UA earth station into terrestrial services

- 17.3-20.2 GHz - interference from terrestrial services into UA earth station

- $27.5-30.0 \mathrm{GHz}$ - interference from UA earth station into terrestrial services 


\section{Spectrum for UAS Control and Non-Payload Communications}

\section{Sharing Studies for WRC-15 Agenda Item 1.5}

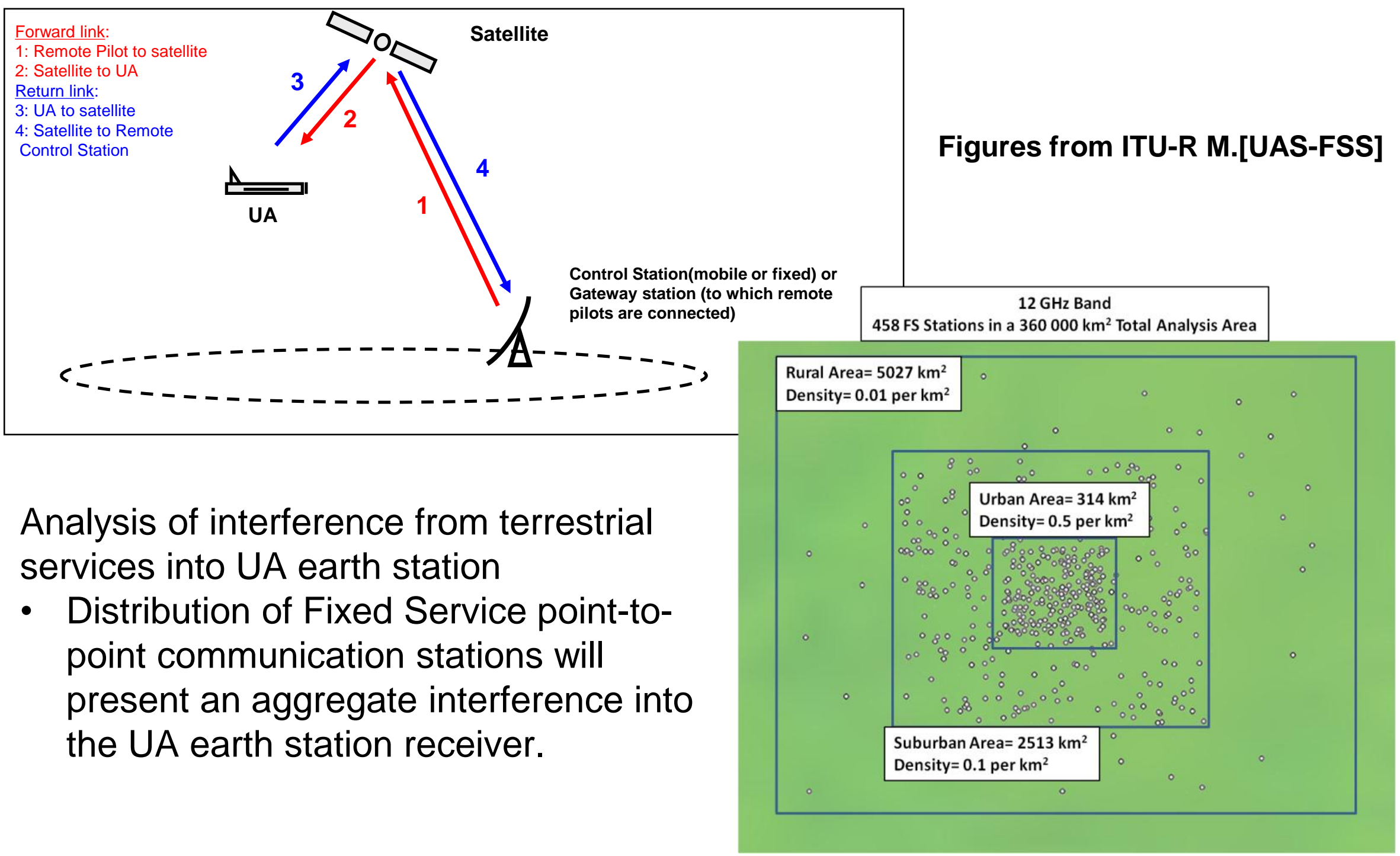




\section{Spectrum for UAS Control and Non-Payload Communications}

\section{Sharing Studies for WRC-15 Agenda Item 1.5}

Analysis of interference from UA earth station into terrestrial services

- UA earth station transmitter will present possible interference into Fixed Service point-to-point communication stations.

- It may be necessary to analyze a distribution of UA, since the UA transmit bandwidth is much smaller than the Fixed Station bandwidth

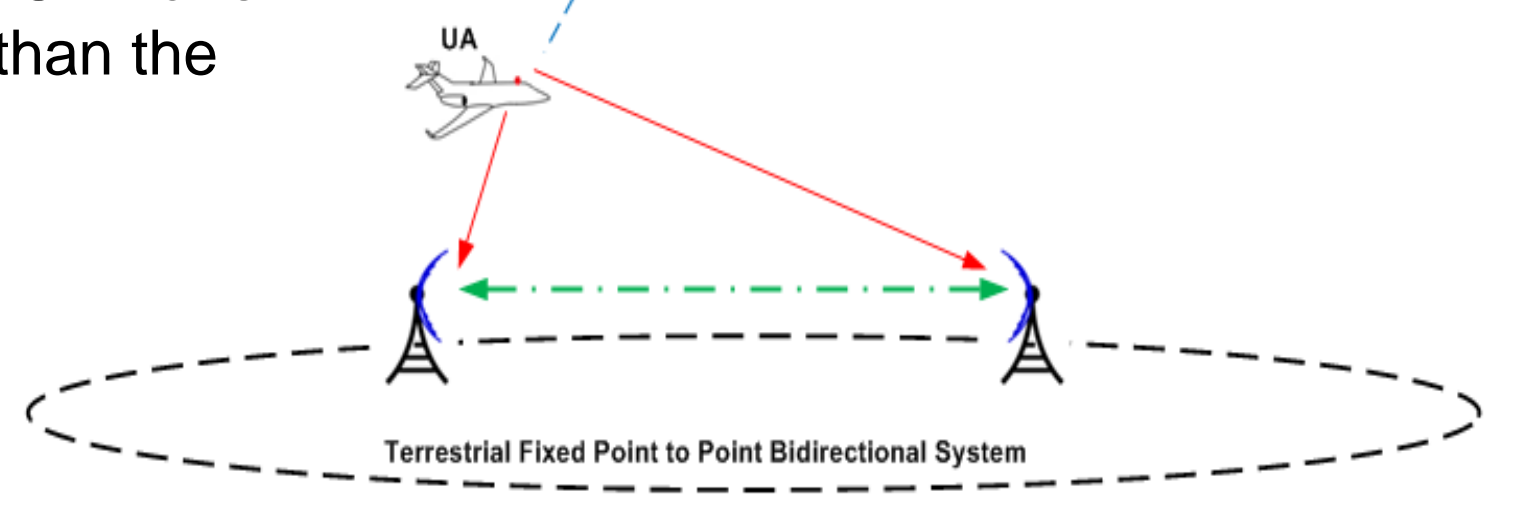




\section{Spectrum for UAS Control and Non-Payload Communications}

\section{Other considerations...}

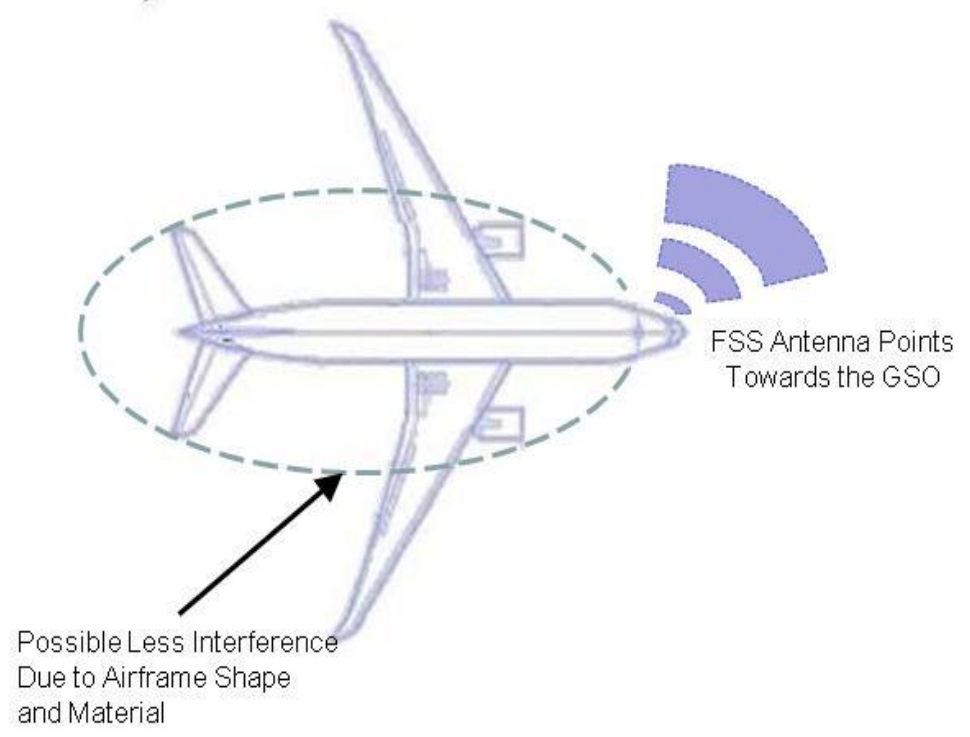

Figure from ITU-R M.[UAS-FSS]

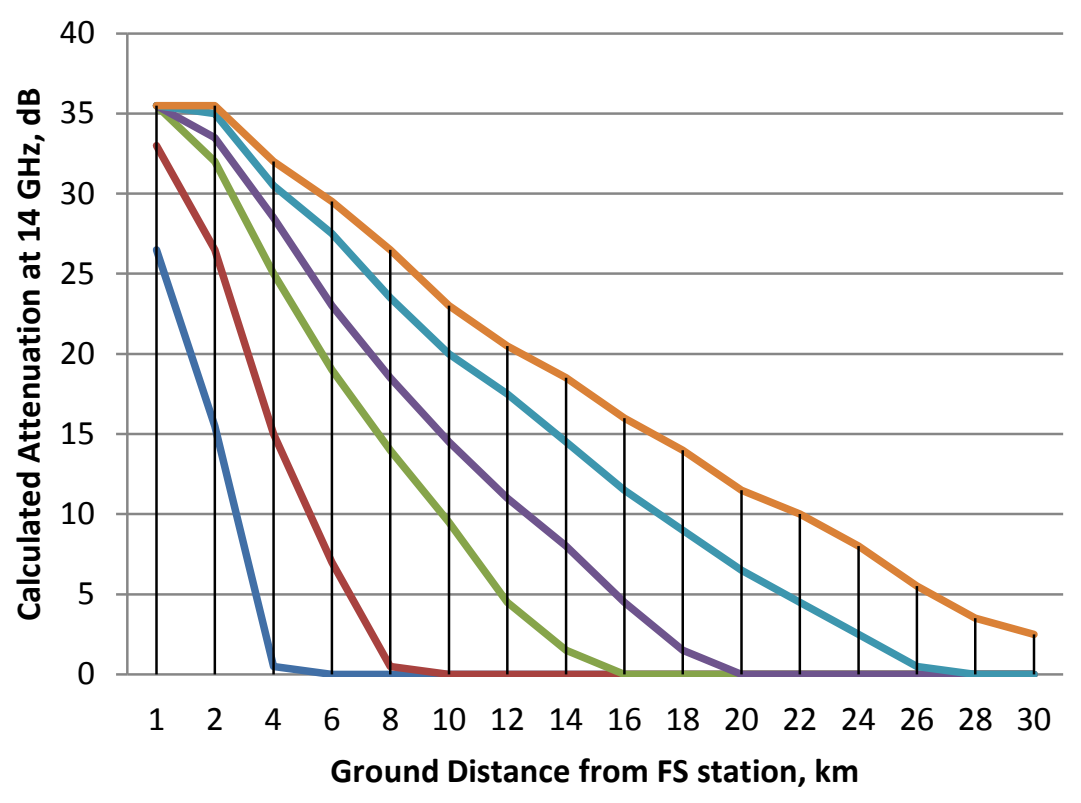

$-5000 \mathrm{ft}$

$10000 \mathrm{ft}$

$18000 \mathrm{ft}$

$24000 \mathrm{ft}$

$-33000 \mathrm{ft}$

$-41000 \mathrm{ft}$

With the earth station antenna mounted on to of the UA, fuselage attenuation relative to points on the ground will occur. 


\section{Spectrum for UAS Control and Non-Payload Communications}

\section{Band Planning - 5030-5091 MHz}

The 5030-5091 MHz Band has an AM(R)S allocation for terrestrial CNPC and also an AMS(R)S allocation for satellite BLOS CNPC.

Possible ways to partition the band are being discussed, although no serious proposals have been offered yet.

- For example, the high and low ends of the band could be designated for satcom $(A M S(R) S)$ and the middle for terrestrial $(A M(R) S)$.

- Should the partition be fixed (easing global interoperability and standardizing system and equipment designs) or flexible (it may be premature to make binding decisions on relative need for terrestrial vs. satcom CNPC).

- With no satellites currently in existence to provide C-Band CNPC service, is it useful to have the entire band available for terrestrial CNPC?

- Some regions might want to use only one or the other of the two CNPC options.

REF: ACP WGF28/WP13(rev1), Frank Box and Warren Wilson, The MITRE Corporation 


\section{Spectrum for UAS Control and Non-Payload Communications}

\section{Summary}

- Control and Non-Payload Communications (CNPC) is a critical enabler for UAS integration into the NAS.

- Protected spectrum for UAS CNPC is a necessity.

- Line-of-Sight (terrestrially provided) and Beyond-Line-of-Sight (provided by satcom) are both required.

- ITU-R gives the spectrum requirements:

- $34 \mathrm{MHz}$ for the terrestrial-based LOS CNPC

- $56 \mathrm{MHz}$ for the satellite based BLOS CNPC links

- LOS CNPC Spectrum has been allocated during WRC-12

- C-Band (5030-5091 MHz) and L-Band (960-977MHz) are allocated.

- BLOS CNPC Satellite Spectrum is still needed

- C-Band allocation unusable in the near term at least; WRC-15 Agenda Item 1.5 considers the use of FSS systems for CNPC. Sharing studies are underway.

- Planning the use of the $5030-5091 \mathrm{MHz}$ band has started, must be done carefully. 


\title{
Spectrum for UAS Control and Non-Payload Communications
}

\section{Thank you!}

\author{
For further information contact: \\ Robert J. Kerczewski \\ NASA Glenn Research Center \\ rkerczewski@nasa.gov
}

